\title{
Reliability analysis of wind embedded power generation system for Indian Scenario
}

\author{
Amit Jain $^{1}$, R. Balasubramanian², S.C. Tripathy ${ }^{3}$ \\ ${ }^{1 *}$ Power Systems Research Center, International Institute of Information Technology, Hyderabad, INDIA \\ ${ }^{2}$ Centre for Energy Studies, Indian Institute of Technology, New Delhi, INDIA \\ ${ }^{3}$ Ghanashyam Hemalata Institute of Technology Management, Puri - 2, Odisha, INDIA \\ *Corresponding Author: e--mail: amit@iiit.ac.in Tel +91-40-66531141, Fax.+91-40-66531413
}

\begin{abstract}
This paper presents a method for Reliability Analysis of wind energy embedded in power generation system for Indian scenario. This is done by evaluating the reliability index, loss of load expectation, for the power generation system with and without integration of wind energy sources in the overall electric power system. In the present study, we have taken Wind energy sources for the description of methodology and simulation results for an Indian power system are presented. The methodology can be utilized for any type of alternative generation sources as it is general in nature and not specific to any particular generation energy source. This paper provides a study in Indian scenario to analyze the effect on system reliability when the percentage of wind energy generation increases in the total power generation of system.
\end{abstract}

Keywords: Electrical systems; Energy sources; Loss of Load; Power; System reliability; Wind energy.

\section{Introduction}

Every nation is looking to renewable energy sources as the alternative source of electric power generation with the ever increasing demand for electrical power. This is very important for future keeping the continuous depletion in the existing reserve and increase in cost of the conventional energy sources in consideration as well as pollution and many other adverse environmental impacts due to them. New technologies for electrical power from sun and wind have been developed and considerable research is being done to further improve their performance and also to understand their effect on the operation and economics of electric power system. The installed global capacity of wind power generation units in commercial operation was nearly 7000 MW by the end of year 2000 (Patel et al, 1999), (Willis et al, 2000). With the technical advancement and encouraging government policies worldwide for increasing the use of wind power for commercial electric power generation, the global wind energy generating capacity had increased to the level of 39294 MW by the end of year 2003 (American Wind Energy Association). At the end of 2009, worldwide nameplate capacity of wind-powered generators was 159.2 gigawatts (GW) (World Wind Energy Association, 2010) and by the end of June 2010 the capacity had risen to 175 GW (WWEA Statistics, 2010). Energy production was 340 TWh, which is about 2\% of worldwide electricity usage (World Wind Energy Association, 2010), (Worldwatch.org) and has doubled in the past three years. Several countries have achieved relatively high levels of wind power penetration, such as $20 \%$ of stationary electricity production in Denmark, 14\% in Ireland (eirgrid.com) and Portugal, 11\% in Spain, and 8\% in Germany in 2009 (Flowers et al). Indian scenario for wind electric energy generation has been very progressive with good growth as India has taken an early initiative in utilization of wind energy for power generation. The Indian wind energy sector has an installed capacity of 11807.00 MW (as on March 31, 2010) (The Indian Wind Energy Association, 2010) which had further increased to level of 12,100 MW by the end of June 2010 (WWEA Statistics, 2010).

As these wind units are being included in the commercial power systems, the fluctuating nature of energy produced by these units, due to changing and not so predictable nature of input energy used in these units, has different effect on the overall system reliability than the energy produced by conventional energy sources. 
This paper presents a study for Reliability Analysis of wind energy embedded electric power system for Indian Scenario. This is done by evaluating the reliability index, loss of load expectation (LOLE), for the power generation system with and without integration of wind energy system in the overall electric power generation system.

\section{Reliability Analysis of Wind Embedded Power Generation System}

2.1 Probabilistic Model of Power Generation System: The availability or random outages of power generation units is calculated as probability density function on the bases of the historic data. The graphical representation of the availability of the generating capacity of a given unit on the bases of historical data is represented as shown in Fig.1.

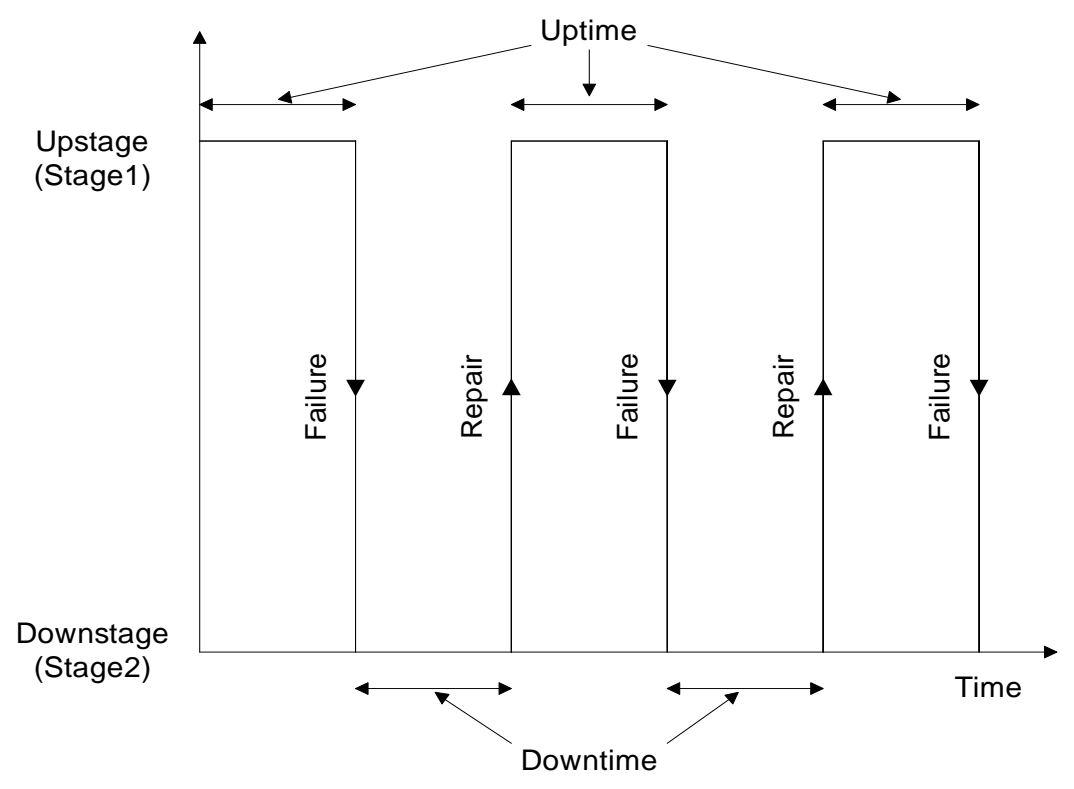

Figure 1. Random unit performance record ignoring schedule outage

The long-term average of power generation unit up time expressed as a fraction of the average cycle time gives the probability that the generation capacity of the unit will be available, also called the unit availability (denoted as p). In the same way, the longterm average of the down time gives the probability that the generating capacity of the unit will be unavailable (denoted by q), also called as the unit forced outage rate (FOR). The probability values $\mathrm{p}$ and $\mathrm{q}$ are probability of the unit being in the up-state at any time $t$ and the probability of the unit in the downstate at any time $t$ respectively (Sullivan et al, 1977), (Endreny et al, 1978). The forced outage capacity probability density function of the unit is depicted in Fig. 2.

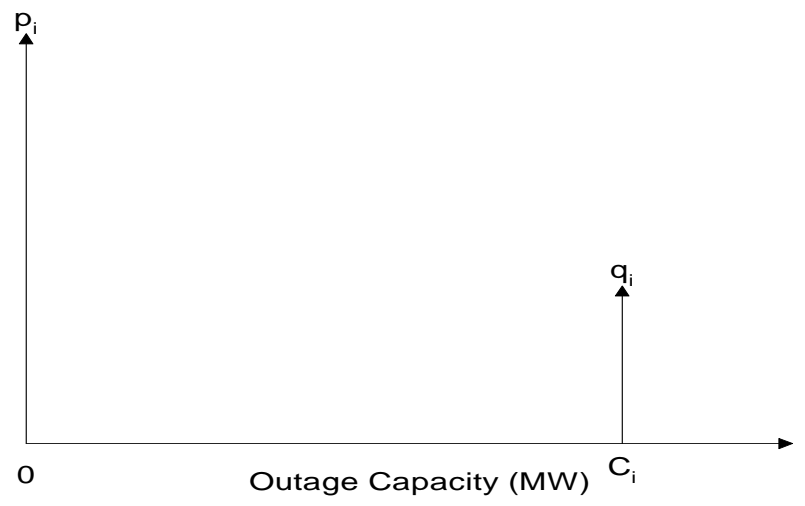

Figure 2. Forced outage capacity probability density function

The reliability analysis for power generation system uses a capacity outage probability table, which is an array of capacity levels and the associate probabilities of existence. This is obtained by combining the generating units' availability and unavailability using basic probability concepts. From the individual probability table, we prepare cumulative probability table (Billinton et al, 
1984). The cumulative probability is the probability of finding a quantity of capacity outage equal to or greater than the indicated amount. In this paper we are using a generation system for the two state units and a recursive algorithm, which adds the units sequentially, is used to build the capacity model of the generation system that is represented as the cumulative probability table.

2.2 Recursive Algorithm for the Probabilistic Capacity Model of the Power Generation System: The cumulative probability of a particular capacity outage state of X MW, after the $\mathrm{i}^{\text {th }}$ unit of capacity $\mathrm{C}_{\mathrm{i}} \mathrm{MW}$ and forced outage rate $\mathrm{U}_{\mathrm{i}}$ are added, is given by

$$
P(X)=\left(1-U_{i}\right) P^{\prime}(X)+U_{i} P^{\prime}\left(X-C_{i}\right)
$$

where $\mathrm{P}^{\prime}(\mathrm{X})$ and $\mathrm{P}(\mathrm{X})$ denote the cumulative probabilities of the capacity outage state of $\mathrm{X}$ MW before and after the $\mathrm{i}^{\text {th }}$ unit is used.

The above expression is initialized by setting

$\mathrm{P}^{\prime}(\mathrm{X})=1.0$ for $\mathrm{X} \leq 0$

and

$\mathrm{P}^{\prime}(\mathrm{X})=0.0$ otherwise

$\mathrm{P}^{\prime}(\mathrm{X}-\mathrm{Ci})=$ Outage capacity $(\mathrm{X}-\mathrm{Ci})$ probability before the ith unit is added.

2.3 Loss of Load Expectation: The technique used to determine whether a power generation system satisfies a desired level of reliability is defined by a reliability index, loss of load expectation (LOLE). A loss of load will occur only when the system load level exceeds the capability of the generating capacity remaining in service. Loss of load expectation is the probability of the power generating units of a system being inadequate to meet the load demand. The capacity outage probability table of the power generation system is convolved with system load characteristics for calculating the loss of load expectation. An hourly peak load variation model is used where its hourly peak load represents each hour; therefore, individual hourly load values are used.

$$
L O L E=P_{i}\left(C_{i}<L_{i}\right)
$$

where,

$\mathrm{Ci} \quad=$ available capacity on hour i

$\mathrm{Li} \quad=$ forecast peak load on hour $\mathrm{i}$

$\mathrm{Pi}(\mathrm{Ci}<\mathrm{Li}) \quad=$ probability of loss of load on hour $\mathrm{i}$

After computing the hourly value of LOLE for all the hours under study, the index for the entire period is computed by:

$$
L O L E=\sum_{k=1}^{n h s} L O L E_{k}
$$

where,

LOLE $\quad=$ loss of load expectation for period under study.

Nhs $\quad=$ number of hours under study

The value of LOLE is in hours.

2.4 Loss of Load Expectation evaluation of Wind Embedded Power Generation System: References For reliability evaluation, the overall system is divided into two subsystems, containing the conventional and wind units, and a generation system model is built using a Recursive Algorithm for each of these two subsystems. Each of the generation system models is described by two mdimensional vectors as follows:
$\mathrm{Ci}=$ ith element of the $\mathrm{C}$ vector
$=$ one of the possible discrete capacity states
$\mathrm{Pi}$
$=$ ith element of $\mathrm{P}$ vector
$=\mathrm{P}(\mathrm{C} \quad \mathrm{Ci})$
$=$ probability of capacity on outage being equal to or greater than $\mathrm{Ci}$
$\mathrm{m}$
$=$ number of generation states

These two generation subsystem probability models are represented by the vectors 
$\begin{array}{ll}\text { CC } & \text { = capacity vector of conventional subsystem } \\ \text { PC } & =\text { probability vector of conventional subsystem } \\ \text { CWIND } & =\text { capacity vector of wind subsystem } \\ \text { PWIND } & \text { = probability vector of wind subsystem }\end{array}$

The power output of the wind subsystem is calculated for each hour under study and a vector containing the hourly output of the wind power generation unit subsystem is created as:

POWINDk= power output of the wind system during the kth hour of the period under study

The probability model of the wind generation subsystem is modified to take into account the effect of the fluctuating energy generation by creating two m-dimensional vectors MWINDk such that:

$$
\operatorname{MWIND}_{k, i}=\frac{\text { CWIND }_{i} \text { POWIND }_{k}}{\text { PRWIND }}
$$

where

$\begin{array}{lll}\text { MWINDk,i } & = & \text { ith element of MWINDk } \\ \text { CWINDi } & = & \text { ith element of CWIND } \\ \text { CWIND } & = & \text { capacity vector of the generation capacity model of the wind subsystem } \\ \text { PRWIND } & = & \text { rated power of wind subsystem }\end{array}$

Each subsystem is treated as multi-state unit and these subsystems are combined to calculate the LOLE for the hour in question. The combination of these multi-state units results in states with capacities given by the equation:

$$
C_{i j}=C C_{i}+C W I N D_{j}
$$

where $i$, and $j$ refer to the states in the first, second and third subsystems respectively and Cij represent an element in twodimensional array C that constitutes all possible capacity states of the combined system. A Discrete State Algorithm is used for evaluating the LOLE of the system for the hour under study, which is as follows:

(1) Initialize by setting

$$
\text { LOLEk } \quad=0.0
$$

where

LOLEk = loss of load expectation for $\mathrm{k}$ hour of study

(1) $\mathrm{J}=1$

(2) $\mathrm{CT}=\mathrm{CCnc}+\mathrm{CWINDnwind}$

where

CT = total capacity

nc $\quad=\quad$ number of states in conventional subsystem

nwind $\quad=\quad$ number of states in wind subsystem

$\mathrm{CCnc} \quad=\quad$ total capacity in conventional subsystem

CWINDnwind $\quad=\quad$ total capacity in wind subsystem

(3) $\mathrm{i}=1$

(4) $\mathrm{Cij}=\mathrm{CCi}+\mathrm{CWINDj}$

If $\mathrm{Cij}$ is equal to or more than (CT - load) for the hour, go to (8)

(5) $\mathrm{i}=\mathrm{i}+1$

If $i$ is less than or equal to nc, go to (5)

(6) If $i$ is more than nc, go to (10)

(7) $\mathrm{b}=\mathrm{i}$

where

b = boundary state defining the loss of load.

(8) LOLEk = LOLEk + PCb (PWINDj - PWINDj+1)

(9) $\mathrm{j} \quad=\mathrm{j}+1$

If $\mathrm{j}$ is less than or equal to nwind, go to (4).

The reliability index for the entire period is computed by the summation of all hourly values of LOLE. 


\section{Simulation Results for Case Study}

The reliability evaluation method has been applied on a small Indian test system with a total capacity of 176 MW. This sample test system and load data have been taken from Gujarat province in western part of India. The test system consists of the units and their FOR given in table 1 (Allan et al, 1986).

Table 1. Data for the test system used for simulation study

\begin{tabular}{|c|c|c|c|}
\hline Unit capacity (MW) & No. of units & Total capacity (MW) & Forced outage rate (FOR) \\
\hline 50 & 2 & 100 & 0.05 \\
\hline 20 & 2 & 40 & 0.08 \\
\hline 12 & 3 & 36 & 0.08 \\
\hline
\end{tabular}

The study was conducted by replacing the 12 MW conventional units one after one, by wind units and this is represented as the penetration level of the wind power in the overall electric generation system (Singh et al, 2010). The details about the wind units are given in Appendix I (Singh et al, 1985). All the units contained in wind system are taken to be identical. Then for different penetration levels of the wind energy sources, reliability indices by embedding the wind units have been simulated for four different months of the year. The flow chart for the reliability index calculation is given in Fig. 3.

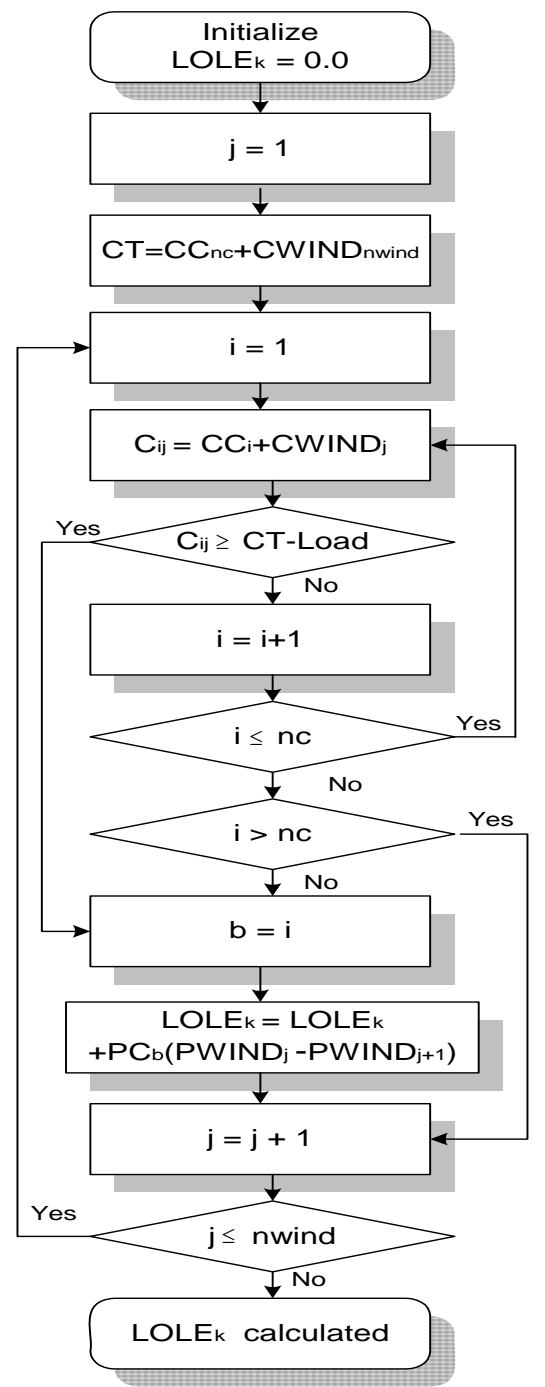

Figure 3. Flow chart for evaluating the LOLE of the system for the $\mathrm{k}^{\text {th }}$ hour 
The wind site selected is Veraval, which has very good wind speed most of the time of the year, in Gujarat province in India. The simulation study was done for the selected test system and wind site, which gives the reliability indices for an Indian power generation system for four different months. The results obtained are presented in table 2.

Table 2. Results of LOLE (Hours) for four different months of a year representing four seasons

\begin{tabular}{|c|c|c|c|c|}
\hline \multirow{2}{*}{ Penetration level (\%) } & March & June & September & December \\
\cline { 2 - 5 } & \multicolumn{4}{|c|}{ LOLE (hours) } \\
\hline 6.8 & 68.70 & 10.87 & 17.34 & 65.92 \\
\hline 13.6 & 80.54 & 12.24 & 30.81 & 79.21 \\
\hline 20.5 & 94.61 & 21.94 & 59.02 & 107.13 \\
\hline
\end{tabular}

Historic data is taken for wind velocity at Veraval in India (Meteorological Department, Government of India). Hourly load data using daily load cycle was used. This simulation study is based on the tacit assumption that during one-month period under consideration, wind speed do not vary significantly from day-to-day and same daily statistics is used for the entire month (Abouzahr et al, 1991). The simulation results for sample Indian electric power system for four months, characterizing different weather conditions of the year, show that the effect of including the wind system on power generation system reliability increases with the increase of wind units penetration level in electric power system because the effects of fluctuating power from wind energy source becomes more dominant. The reliability for this wind embedded Indian system is good in summer season as wind speed is very high most of the time in summer resulting in near rated power generation most of the time. The winter and spring season has high wind velocity intermittently resulting in generation of large power at those times but the mismatch in the high load demand time and high wind power generation time result in poor reliability of the overall system. In general one can see that the negative effect on overall system reliability becomes more dominant once wind penetration level becomes more significant.

\section{Summary}

Reliability analysis of wind embedded power generation system for Indian scenario has been presented in this paper where a small Indian power generation system and a wind site in Gujarat province of India has been considered for the study. The probabilistic capacity generation model of wind energy system is modified hourly to incorporate the fluctuating nature of the wind energy system and then the entire generation systems reliability, which is represented as loss of load expectation (LOLE), is evaluated using the discrete state algorithm. The simulation study has been done on the small Indian power generation system for four months, characterizing different weather condition of the year, and reliability index (LOLE) with increasing penetration level of wind energy source are presented. The simulation results of the study for Indian scenario shows that increasing the wind penetration in power generation system has negative impact on system reliability even if wind generation site considered in the study has very good wind speed most of the time. Therefore, present study for an Indian scenario provides insight to the planners about the reliability deterioration for power generation system with increasing level of wind power penetration and will help in planning the optimal level of wind penetration for Indian power generation systems.

\section{Appendix}

Wind turbine system units of $500 \mathrm{KW}$ capacity with $\mathrm{FOR}=0.03$ were used in this paper. The wind speed data for these units is:

$\begin{array}{lllll}\mathrm{Vci} & = & \text { Cut-in velocity } & = & 12.6 \mathrm{kmph} \\ \mathrm{Vr} & = & \text { Rated velocity } & = & 32.4 \mathrm{kmph} \\ \mathrm{Vco} & = & \text { Cut-off velocity } & = & 69.0 \mathrm{kmph}\end{array}$

The power output of these units was calculated using the following equations:

$$
\begin{gathered}
P O W=\left\{\begin{array}{cc}
0.0 & 0<V<V_{c i} \\
A+B V+C V^{2} & V_{c i}<V<V_{r} \\
P R W & V_{r}<V<V_{c o} \\
0.0 & V>V_{c o}
\end{array}\right. \\
A=\frac{1}{\left(V_{c i}-V_{r}\right)^{2}}\left[V_{c i}\left(V_{c i}+V_{r}\right)-4\left(V_{c i} V_{r}\right)\left(\frac{V_{c i}+V_{r}}{2 V_{r}}\right)^{3}\right]
\end{gathered}
$$




$$
\begin{gathered}
B=\frac{1}{\left(V_{c i}-V_{r}\right)^{2}}\left[4\left(V_{c i}+V_{r}\right)\left(\frac{V_{c i}+V_{r}}{2 V_{r}}\right)^{3}-\left(3 V_{c i}+V_{r}\right)\right] \\
C=\frac{1}{\left(V_{c i}-V_{r}\right)^{2}}\left[2-4\left(\frac{V_{c i}+V_{r}}{2 V_{r}}\right)^{3}\right]
\end{gathered}
$$

where, $\mathrm{V} \quad$ = $\quad$ wind velocity for the hour in question

PRW $\quad$ rated power of the unit

\section{References}

Abouzahr, I., and Ramkumar, R. 1991. An Approach to Assess the Performance of Utility-Interactive Wind Electric Conversion Systems. IEEE Trans. Energy Conversion, Vol. 6, pp. 627-638.

Allan, R. N., Billinton, R., and Abdel-Gawad, N. M. K. 1986. The IEEE Reliability Test System - Extensions to and Evaluation of the Generating System. IEEE Trans. Power Systems, PWRS-1, pp. 1-7.

American Wind Energy Association. Wind Energy Fast Fact. http://www.awea.org

Billinton, R. 1984. Reliability evaluation of Power System. Pitman Books, London. eirgrid.com. Renewables. http://www.eirgrid.com/renewables/.

Endreny, J. 1978. Reliability Modelling in Electric Power System. John Wiley and sons, Chicester.

Flowers, Larry. Wind Energy Update. Wind Engineering. 191-200, http://www.windpoweringamerica.gov/.

Meteorological Department, Government of India. Weather Report.

Patel, M. R. 1999. Wind and Solar Power Systems. CRC Press, Boca Raton, Florida: CRC Press LLC.

Singh, Chanan, and Bagchi, Arijit. 2010. Reliability Analysis of Power Systems Incorporating Renewable Energy Sources.

Proceedings of 16th National Power Systems Conference (NPSC) 2010, Hyderabad, India, 15-17 December.

Singh, C., and Lago-Gonzalez, A. 1985. Reliability Modelling of Generation Systems Including Unconventional Energy Sources.

IEEE Trans. Power Apparatus and Systems, PAS-104, pp. 1049-1056.

Sullivan, R. L. 1977. Power System Planning, McGraw Hill, New York.

The Indian Wind Energy Association (InWEA), http://www.inwea.org/index.htm.

Willis, H. L., and Scott, W. G. 2000. Distributed Power Generation, Planning and Evaluation, Marcel Dekker, Inc.

Worldwatch.org. Wind Power Increase in 2008 Exceeds 10-year Average Growth Rate. http://www.worldwatch.org/node/.

World Wind Energy Association. 2010. World Wind Energy Report 2009. World Wind Energy Association. February,

http://www.wwindea.org/home/images/stories/worldwindenergyreport2009_s.pdf.

WWEA Statistics June 2010. http://www.wwindea.org/home/ .

\section{Biographical notes}

Amit Jain graduated from KNIT, India in Electrical Engineering. He completed his masters and Ph.D. from Indian Institute of Technology, New Delhi, India. He was working in Alstom on the power SCADA systems. He worked in Korea in 2002 as a Post-doctoral researcher in the Brain Korea 21 project team of Chungbuk National University. He was Post Doctoral Fellow of the Japan Society for the Promotion of Science (JSPS) at Tohoku University, Sendai, Japan. He also worked as a Post Doctoral Researcher at Tohoku University, Sendai, Japan. Currently he is heading, Power Systems Research Center at IIIT, Hyderabad, India. His fields of research interest are IT applications in Power and Energy Systems, power system real time monitoring and control, artificial intelligence applications, smart grid, power system planning and economics, electricity markets, renewable energy, and reliability analysis.

R. Balasubramanian obtained his Ph.D. degree from IIT Kanpur. He is a professor at Indian Institute of Technology, New Delhi, India. He is a senior member of IEEE. He was chairman of IEEE Delhi section for year 2001 and 2002. His areas of research include Power System Planning, Operation \& Control, Energy System Modelling \& Management, and Power from Non-conventional Energy Sources including Energy Storage Devices. He has guided more than 10 doctoral scholars and published about 80 research papers in the national and international journals of repute.

S. C. Tripathy obtained his Ph.D. degree in Electrical Engineering from University of Minnesota, Minneapolis, USA in 1970 . Then he joined the faculty of the Indian Institute of Technology, New Delhi, India. He was professor there till he retired in 1998. He is currently a professor and principal at Ghanashyam Hemalata Institute of Technology Management, Puri, Odisha, India. He had also been Head of the Center for Energy Studies at Indian Institute of Technology, New Delhi. He is Fellow of IEE (London) and IE (India). He has been visiting professor to many reputed universities in Europe and Canada. His fields of interest are Electric Power System Analysis and Control.

Received February 2011

Accepted March 2011

Final acceptance in revised form May 2011 